$\Phi=\Phi$

\title{
Paradigmatic perspectives of a psychosocial educational programme to facilitate the reintegration of incarcerated women who had dumped babies and / or committed infanticide in Namibia
}

\author{
Sumpi Ndempavali *, Amukugo Hans Justus \\ Lecturers, School of Nursing and School of Public Health, Faculty of Health Sciences University of Namibia \\ *Corresponding author E-mail: nsumpi@unam.na
}

\begin{abstract}
The aim this paper is to discuss the paradigm perspective used in a developing a psychosocial educational programme to facilitate the reintegration of incarcerated women who had dumped babies and / or committed infanticide. A study of this nature requires a paradigmatic perspective; this is a collection of logically linked concepts and propositions that provide a theoretical perspective or orientation that tends to guide the research approach to a specific topic.

A paradigmatic perspective as a "way of looking at natural phenomena that encompasses [sic] a set of philosophical assumptions, and [sic] that guides the researcher's approach to inquiry". It represents a worldview that defines for its holder, the nature of the "world," the individual's place in it, and the range of possible relationships to that world and its parts have, which include cosmological and theological points of view. Polit and Hungler (2006) describe assumptions as basic principles that are accepted as true on the basis of logic or reasoning, but without proof or verification.

The paradigmatic perspective in this study consisted assumptions and the retries. These assumptions include the meta-theoretical, ontological, epistemological, axiological, and methodological assumptions. The meta theoretical basis of the study are Dickoff, James and Wiedenbach's (1968) practice theory; Kolb's experiential learning theory and Knowles' andragogical learning theory.
\end{abstract}

Keywords: Paradigmatic Perspectives; Psychosocial Educational Programme; Facilitate; Reintegration Incarcerated Women; Dumped Babies and Infanticide.

\section{Introduction}

This section of the study presents the motivation to conduct the study based on the enormity of baby dumping and infanticide and its impact on the general public the Namibian nation. The Final Draft for the National Gender Action Plan for the Ministry of Gender Equality and Child Welfare (2011) which is aligned to the SADC Protocol on Gender and Development and the Millennium Development Goals, seven clusters were developed. One of the strategies in the second cluster deals with reproductive health among others to ensure access to and knowledge about health, sexual and reproductive services, and to enhance public education and awareness about, for example sexual reproductive health and baby dumping. The strategy requires actions to implement the national campaigns on sexual reproductive health, including baby dumping. Other actions include lobbying relevant ministries to ensure that a full range of reproductive health-care services; such as family planning, parental care, antenatal care, delivery and postnatal care, as well as other reproductive and sexual health conditions are accessible and affordable to all users.

Timms (2005) states that one reason why women commit infanticide and / or dump their babies could be due to a condition called "puerperal psychosis". "Puerperal" means the six weeks after having a baby and "psychosis" is a serious mental illness. So, "puerperal psychosis" refer to a serious mental illness in a woman short- ly after she has given birth. Puerperal psychosis is most likely to be due to the effect of the huge hormonal changes that happen at the end of pregnancy and giving birth. Puerperal psychosis is rather rare and has a prevalence rate of 1 in 500 births.

In order to address the growing problem of baby dumping and improving the lives of the children instead, the Legal Assistance Center (2011) has called for an enactment of the Child Care and Protection Act. The Act has been opened to public debate because Namibia does not know yet how to tackle this problem. Kangandjera and Mapaure (2009) state that in any caring society, the importance of child welfare cannot be overemphasised because the future welfare of the entire community, as well as its growth and development depend on the health and well-being of its children. Children need to be regarded as valuable national assets because the future well-being of the nation depends on how its children grow up and develop.

Greiner (2001-2008) mentions that some parents in Nigeria recklessly abandon their babies in streets while other ones take them to orphanages and beg workers to take them, and some women even give birth at orphanages. Such kids are being taken to social welfare, are registered with the government, and are distributed to orphanages. Various orphanages have been established all over Nigeria to ensure that such babies have a comfortable home. The Gauteng Province in South Africa, dumping babies are increasingly becoming a large part of non-natural, undetermined deaths in the zero to four-year age group. These babies are dumped in dust- 
bins and gutters, some are aborted or miscarried, and new-borns are disposed. This behaviour represents $60 \%$ of undetermined deaths of young children (Ramaklas, 2010). Some community members have come up with a facility that is called "Baby Moses" in their endeavour to make a difference. From "Baby Moses", the children are placed with families, put into foster care, taken into private homes, and some are adopted (Daily Maverick, 2012).

Modie-Moroka (2011) mentions that there is a familiar but shocking catalogue of stories; for example, lifeless infants being dragged by dogs, foetuses blocking flush toilets, desperate cries of infants in pit-latrines, children lying cold at the roadside, and live babies saved from pit latrines who are covered in human excreta. Police records between 2005 and 2010 in Botswana indicate that at least 450 babies have suffered this fate. Botswana has designed separate offences for those who commit infanticide, since they acknowledge that there may have been exceptional circumstances involved in the crime. The government of Botswana states that it is in essence a challenge for the government to put in place structures for baby dumping that will promote the wellbeing of the child as outlined in the Children's Act of 2009. Modie-Moroka (2011) also mentions that the establishments of safe haven centres are long overdue and DNA banks should be established to help trace the parents of the abandoned babies. This intervention should promote responsibility and readiness for parenthood by both parents while deterring many from committing this kind of offence (Dzimiri, 2013).

Similar cases of baby dumping are found in Malaysia where people who are responsible for dumping babies who subsequently die would be investigated for murder while abandoned babies who are found alive would be classified and investigated as cases of attempted murder (Salam, 2013). In Kuala Lumpur, the capital city of Malaysia, the baby dumping statistics are critical as mentioned in the introduction. A comparative research project in Malaysia (Mazbah, T., Abdullah, N., Jaafar, N. I. M., Tagaranao, M. S. \& Safian, Y. H. M. (2014) strongly suggests that baby dumping offender ought to be penalised. They state that there is a need to create and increase awareness about unwanted pregnancies while emphasising that studies need to be conducted to assess the level of awareness among the target group and also to examine the provision of alternative or preventive measures, such as baby hatches. The availability of preventive methods does not aim at encouraging a crime; it aims at avoiding more babies being dumped at dangerous places and the increased possibility of death. As a recommendation, they state that it is perhaps necessary to introduce a new law or section in the Penal Code with regard to baby dumping that clarifies the definition of baby dumping and identifies who specifically could be penalised for this crime. At the moment, legislation about baby dumping does not exist in Malaysia. They also emphasise the establishment of orphan care interventions because an increasing number of babies are being abandoned or dumped in unimaginable places; such as waste dumps, bushes, drains, and public toilets.

In Hamburg, Fernandez (2008) mentions that baby hatches opened in 2000 and since then more than 200 have opened across Germany, providing places of safety and care for abandoned babies. He also states that there are $40-60$ babies killed in Germany every year and that their bodies are found in the toilets, forests, attics, and carrier bags. There is no denying that baby dumping has become a grave social phenomenon that is drawing nationwide attention in China. In general, the infants who are discarded are born either out of wedlock, with some physical deformity, or in violation of governmental family planning regulations. The family planning policy, known as the one-child policy, is a population control policy of the People's Republic of China. As a result, the overwhelming majority of these discarded babies are girls, victims of traditional ideas that value men and disparage women. Chinese authorities have built a "baby abandonment" building where parents can anonymously leave their unwanted children.

Literature mentions two types of infanticide: On the one hand healthy but unwanted children are killed, and on the other hand ill, malformed, weak, or sickly babies are killed (Moseley, 1986).
Roman and certain other ancient cultures regarded the birth of a deformed baby as a bad omen, therefore, babies who were born with even a minor defect, such as a cleft palate or missing finger, were put to death (Moseley, 1986). Infanticide used to be practiced for various reasons; a baby being born out of wedlock, economic reasons, population control, and ridding society of potentially burdensome deformed members (Moseley, 1986).

Baby dumping is also attributed to reasons such as lack of communication. According to the MGECW (2009), it is difficult for young people to communicate with their immediate family members, extended family members, and even with people in their community about pregnancy; hence pregnancies are usually concealed for as long as possible. Furthermore, infanticide and baby dumping are regarded as the result of rape or incest that goes unreported due to stigma, especially when it is committed by a family member. Forced sex constitutes a significant problem for Namibian youth. Existing research suggests that as many as $10-15 \%$ of young people have been victims of coercive sex (Schwarz, 2003).

The Secretary General of the Council of Churches in Namibia (CCN) mentions that mothers dump babies for cultural and economic reasons. Included in these reasons are fears of rejection for having a child outside marriage, fear of having to leave school, the inability to support the child financially, and a lack of knowledge about where to take the child for either fostering or adoption. Until this knowledge gap is closed, it is necessary to provide pregnant women with better information about safely handing over their child for care when they do not want to keep the children. Bentu (2013) notes a similar profile to the one mentioned by the Secretary General of the CCN about women who abandon, conceal, or kill their infants. He mentions that while most of them are poor, some of them are from affluent families. They usually are single, and under the age of twenty-five, often first-time mothers or less educated.

Bentu (2013) points out that women who dump their infants generally do not receive any prenatal care, neither have they made plans for the birth or care of their child. Furthermore, they are often not mature enough to thoughtfully weigh their options or the consequences of their actions. Reasons for dumping their infants include extramarital paternity, rape, illegitimacy, and perceiving the child as an obstacle to personal achievement. Bentu (2013) notes that resorting to infanticide and baby dumping for some women may be a response to chronic strains that result from deprivations, vulnerabilities, and a desire for alternative forms of survival. She says that a young woman with poor education, no vocational skills, and a number of dependent children experiences multiple barriers.

According to UNICEF / UNAIDS / WHO (2002), HIV and AIDS seem to be contributing to infanticide and / or baby dumping among women and adolescent girls because it is estimated that $50 \%$ of all new infections occur among young people aged between 15 and 24 years. When women assume that the baby might be HIV positive due to their own status, they may decide to dump the baby (Kopelman \& Van Niekerk, 2005). The Community Agency for Social Enquiry (2007) remarks that the high unemployment rate among women (39\%) and men (28\%) respectively may be another reason for infanticide and / or baby dumping. Infanticide and baby dumping have extremely negative and divisive effects on society. Efforts to understand and deal with these effects in a more holistic manner are called for (Sasman, 2010). The effects include abandonment by the partner, temporary absence from school, loss of a job, dishonour of the family when the girl is unmarried, disease, or death.

The Legal Assistance Centre (LAC) (2008) is of the opinion that women need better access to information about reproductive health, actions after being raped, the legal aspects of abortion, and claiming maintenance. The LAC adds that having a baby can be very difficult for a mother if she does not have the information that she needs and that many do not know about the options available to them. Hubbard of the LAC (2008) states that baby dumping and infanticide in essence is cries for help because young 
mothers may be overwhelmed by the idea of parenthood. They may have difficulty coping with the drastic physical and emotional changes they are experiencing. They may be suffering from depression sometimes brought on by the hormonal changes associated with giving birth. They may be convinced that they would be unable to provide for the child while feeling that there is no one they can turn to for help. They may fear the shame of having given birth outside of marriage. They may fear inability to continue their studies.

A study of this nature requires a paradigmatic perspective that provides a theoretical perspective or orientation that tends to guide the research approach to a specific topic. These assumptions in this study include the meta-theoretical, ontological, epistemological, axiological, and methodological assumptions. The meta theoretical basis of the study are Dickoff, James and Wiedenbach's (1968) practice theory; Kolb's experiential learning theory and Knowles' andragogical learning theory.

\section{Aim of the study}

The aim of the study was to develop, describe, implement, and evaluate a psycho-social training programme to facilitate the reintegration of the imprisoned women who had dumped and / or committed infanticide in the Oshana Region of Namibia.

\section{Objectives of the study}

The following objectives support the aim of study to:

- Explore and describe the experiences of women who had dumped their babies and / or committed infanticide in the Oshana Region.

- Describe a conceptual framework that facilitates the development of the psychosocial training programme for women who had committed infanticide and / or dumped their babies in the Oshana Region.

- Develop and describe a psychosocial training programme for women who had dumped babies and / or committed infanticide in the Oshana Region.

- Implement and evaluate a psychosocial training programme for women who had dumped babies and / or committed infanticide in the Oshana Region.

\section{Significance of the study}

Firstly, this study sought to contribute to an understanding of the challenges that imprisoned women who had committed infanticide and / or dumped babies were experiencing with regard to their fear of reintegration into society. Secondly, the psychosocial training programme developed from the study findings aimed at facilitating the successful reintegration of these women into society.

\section{Paradigmatic perspectives of the research}

Polit and Beck (2012) describes a paradigmatic perspective as a "way of looking at natural phenomena that encompasses [sic] a set of philosophical assumptions, and [sic] that guides the researcher's approach to inquiry". According to Guba and Lincoln (2005), a paradigm may be viewed as a set of basic beliefs (or metaphysics) that deals with ultimates or first principles. It represents a worldview that defines for its holder, the nature of the "world," the individual's place in it, and the range of possible relationships to that world and its parts have, which include cosmological and theological points of view. The beliefs are fundamental, since they have to be accepted simply on faith (however well argued); there is no way of establishing their ultimate truthfulness.

Polit and Hungler (2006) describe assumptions as basic principles that are accepted as true on the basis of logic or reasoning, but without proof or verification. In turn, Burns and Grove (2009) define an assumption as a proposition or statement that is either considered to be true or self-evident on the basis of satisfactorily conducted research. In view of the fact that assumptions are regarded as axioms / proverbs, a researcher does neither question their truth value, nor submit them to empirical testing. The truth of the assumptions is accepted for the purpose of the study at hand. Mouton (2004) states that assumptions function as foundational beliefs or statements that support whatever decisions a researcher makes during the research process. These assumptions include the meta-theoretical, ontological, epistemological, axiological, and methodological assumptions.

\section{Meta-theoretical assumptions}

Botes (1995) states that meta-theoretical assumptions are not testable, deal with the human beings and society, and have their origin in philosophy. According to Botes (1995), meta-theoretical or meta-paradigm assumptions influence the research decisions throughout and serve as a framework within which theoretical statements are made. Creswell (2013) suggests that the following four fundamental interrelated questions should be asked by an inquirer in order to understand the assumptions.

Table 1lists the assumptions of the naturalistic paradigm used in this study to address the basic philosophical questions.

Table 1: Major Assumptions of a Naturalistic Paradigm

\begin{tabular}{ll}
\hline Assumption & Naturalistic paradigm \\
\hline $\begin{array}{l}\text { Ontological } \\
\text { What is the nature of reali- } \\
\text { ty in this study? }\end{array}$ & $\begin{array}{l}\text { Realities of the lived world of women who } \\
\text { had dumped babies and / or committed } \\
\text { infanticide were explored. }\end{array}$ \\
$\begin{array}{l}\text { Epistemological } \\
\text { What is the relationship } \\
\text { between an inquirer and } \\
\text { the research phenomenon? }\end{array}$ & $\begin{array}{l}\text { tured interviews. Subjective interaction was } \\
\text { thus facilitated and it was assumed that } \\
\text { Axiological }\end{array}$ \\
$\begin{array}{l}\text { What is the role of values } \\
\text { in an inquiry? }\end{array}$ & $\begin{array}{l}\text { Subjective interaction and values were } \\
\text { inevitable and essential in this study. }\end{array}$ \\
& $\begin{array}{l}\text { Qualitative, explorative, descriptive, and } \\
\text { Methodology }\end{array}$ \\
$\begin{array}{l}\text { How should an inquirer } \\
\text { obtain knowledge? }\end{array}$ & $\begin{array}{l}\text { contextual research methods were used to } \\
\text { conduct the study. The participants shared } \\
\text { their life experiences of baby dumping and } \\
\text { infanticide. }\end{array}$ \\
\hline
\end{tabular}

\subsection{Ontological assumption}

Ontological assumptions are those assumptions that are concerned with the nature of the reality of a research participant in its various dimensions, therefore, ontological assumptions are implicit in our understanding of human nature (Kimberly, 2009). The research question that needed to be answered was: "What is the nature of reality as perceived by the research participants in various situations?" Creswell (2009) holds the point of view that reality is constructed by individual involved in the research situation. The reality in this study is the adolescent mothers' experiences who had dumped babies and / or committed infanticide. According to Coady and Lehman (2008), reality is created as a consequence of an individual's perceptions and reaction to external stimuli to which that individual responds. Coady and Lehman (2008) also argues that reality is subjective and each individual's creation of reality is unique and independently formulated. Therefore, we as human beings create our own understanding of the phenomena that surround us by reflecting on our experiences. Edmonds \& Kennedy (2013) note that "reality" arises from each individual's perception of his / her experience, for example dumping a baby and / or committing infanticide. Ontology attempts to explain how the phenomenon is subjectively perceived and analysed by a researcher and participants to extrapolate the universal truth about a particular phenomenon. Hence, there is no single reality; there are multiple realities constructed by an individual from her / his own perception and interpretation of a given phenomenon (Edmonds \& Kennedy, 2013). 
In this study, multiple realities comprised multiple experiences; i.e. the realities of the researcher, the participants, and the readers who are interpreting the study. The researcher used direct quotations from interviews as supporting information. Data that had been gained from observations and interactions during the interviews were divided into sets of themes and summarised in order to provide clear meanings that reflected the lived experiences of women who had dumped and / or committed infanticide (Mertens, 2009). The reality of this study was complex, since it was built on the variety of individual opinions of the study participants.

\subsection{Epistemological assumption}

Epistemology, as a technical term in philosophy, refers to how we know; the relationship between the knower and the known (Creswell, 2013). According to Repko (2012), epistemology is the branch of philosophy that studies how one knows what is truth and how one validates truth.

The question that needed to be answered with epistemological assumption is: "What is the relationship between the inquirer and the participants?" In this study, the researcher facilitated and conducted unstructured in-depth face-to-face interviews that were large subjective. The purpose of gathering information during the interaction with women who had dumped babies and / or committed infanticide through the interviews was to enable the researcher to gain knowledge about experiences of the women's fear of reintegration. Therefore, it was necessary for the researcher to conduct unstructured in-depth interviews with the women who had dumped babies and / or committed infanticide with the aim of getting answers since the truth was captured in the reality that they built for themselves. This truth aided the researcher with obtaining knowledge with regard to the fear these women had about the extensive reintegration process. The time spent with the participants during the interviews enhanced the researcher's understanding of the importance of the context. The findings of this study were the result of interaction between the researcher and the participants through face-to-face individual interviews. The researcher assumed that the knowledge gained through these interviews maximized the findings. For that reason, the researcher openly discussed findings / values with the participants. Furthermore, the researcher considered the findings / values as the shaped interpretation of the researcher, as well as the participants (Creswell, 2009).

\subsection{Axiological assumption}

The axiological assumption needs to answer the question of: What is the role of values in the inquiry? In this study, the subjective interaction between the researcher and the participants in the context of their respective values was inevitable and essential. Axiology is considered as the study of "being", therefore, it influences how people view themselves in relationship with others.

Polit and Beck (2008) state that the inquiry should focus on the "subjective and non-quantifiable", i.e. the context determines the boundaries of the inquiry. The individual aspects of phenomena are captured within the context of individual experiences, for example the experiences of women who have dumped babies and / or committed infanticide. The researcher acknowledged that qualitative research is value laden and exposed to biases. In this study, the values of the different identified groups, such as the researcher and women who had dumped babies and / or committed infanticide, determined the context. This study added value, since the availability of the training programme facilitated the reintegration of women had dumped babies and / or committed infanticide.

\subsection{Methodological assumption}

Methodology refers to the best ways and means of obtaining evidence. In order to clarify the methodological assumptions about the accuracy of the information contained in the data, it is incumbent on a researcher to explain the steps he / she needs to take in order to justify the applicability of the information obtained from the participants (Creswell, 2007). In this study, the research process was based on a qualitative naturalistic methodology. The naturalistic methodological assumption emphasises the desirability to present the entire narrated information of the participants, as well as to contextualise the entire phenomenon (Polit \& Beck, 2009). For the purpose of this study, an inductive process and the interpretation of narrated information from women who had dumped babies and / or committed infanticide were used. The findings were qualitatively analysed and findings were based on the results that identified the need to facilitate the reintegration of the imprisoned women who had dumped babies and / or committed infanticide in the society. The findings of this study and the implementation of the psychosocial training programme can be replicated in any appropriate context.

\subsection{Rhetorical assumption}

These meta-theoretical assumptions deal with human beings and society; therefore, they provide an essential framework for theoretical assumption of this study. In this study, rhetorical assumption was important because it meant that what the researcher was reporting was based on what she had observed in the most objective way possible. A rhetorical assumption does not concern itself with gathering quantitative data and performing statistical calculations. Rather, the rhetorical style of this research report had a more humanistic approach that sought to thoroughly interpret and describe the research results.

\section{Theoretical basis of the study}

Theoretical frameworks are testable for they offer epistemic pronouncements about the research field and give shape to the conceptual framework of a research project (Botes, 1995). The theories that were used during the course of this study were Dickhoff, James and Wiedenbach's (1968) practice-orientated theory, Kolb's learning theory, and Knowles' andragogical learning. Dickoff, James and Wiedenbach's (1968) practice theory

Dickhoff et al.'s (1968) practice-orientated theory was utilised to achieve the purpose of the study, namely to facilitate the reintegration into the society of previously imprisoned women who had dumped babies and / or committed infanticide. The activities that Dickhoff et al. (1968) included in their situation producing theory were used as a reasoning map. The reasoning map is described in Chapter 4.

This study used the concepts in the survey list drawn up by Dickoff et al. (1968) that included the concepts of agent, recipient, dynamics, procedure, context, and terminus. The survey list formed the basis of the reasoning map:

- The agent is the one who has the required knowledge and is capable of performing activities identified that are related to the problem (Dickoff et al., 1968). In the context of this study, the agent was the researcher in the capacity of lecturer and facilitator who implemented the training programme that had been developed in the context of this study.

- The recipient is the beneficiary of the activities designed by an agent. In this study, women who had dumped babies and / or committed infanticide were the beneficiaries of the training programme.

- The context is regarded as the environment where the activities take place. In this study, the lived experiences of women who had dumped babies and / or committed infanticide were explored in the environment where it took place.

- The procedure is the technique that guides the activities. In this study, the procedure was the training programme that facilitated the reintegration of the previously imprisoned women who had dumped babies and / or committed infanticide in their respective societies.

- The dynamics are guiding rules, protocols, or techniques to be followed while activities are taking place and they facili- 
tate a positive outcome; in this study, the outcome was the successful reintegration women.

- The terminus denotes activities and goals in which an individual is involved. In this study, the terminus encompassed the activities that were identified to address the reality of women who had dumped babies and / or committed infanticide.

The conceptual framework used in this study provided the basis for the development of an educational programme to facilitate the reintegration of imprisoned women who had dumped babies and / or committed infanticide in the society.

\subsection{Kolb's experiential learning theory}

Kolb's theory of experiential learning guided the procedure and the technique during the implementation of the psychosocial training programme as illustrated in Chapter 5 and 6. Kolb's model works according to a four-stage cycle that includes:
Concrete experience - doing or having an experience; this kind of learning results from discussions and feedback from other participants.

Reflective observation - reviewing and reflecting on experiences; this kind of learning comprises the observation of other people or reflective activities, such as role playing.

Abstract conceptualisation - concluding or learning from experience; this is learning from authority in directed learning situations, for example learning from lecture presentations and learning by constructing own conclusions.

Active experimentation - preparation and implementation of what was learnt; this kind of learning comprises active learning through experimentation; for example, engaging in group discussions, case studies, and simulations. Figure 1.2 outlines Kolb's' four-stage learning cycle.

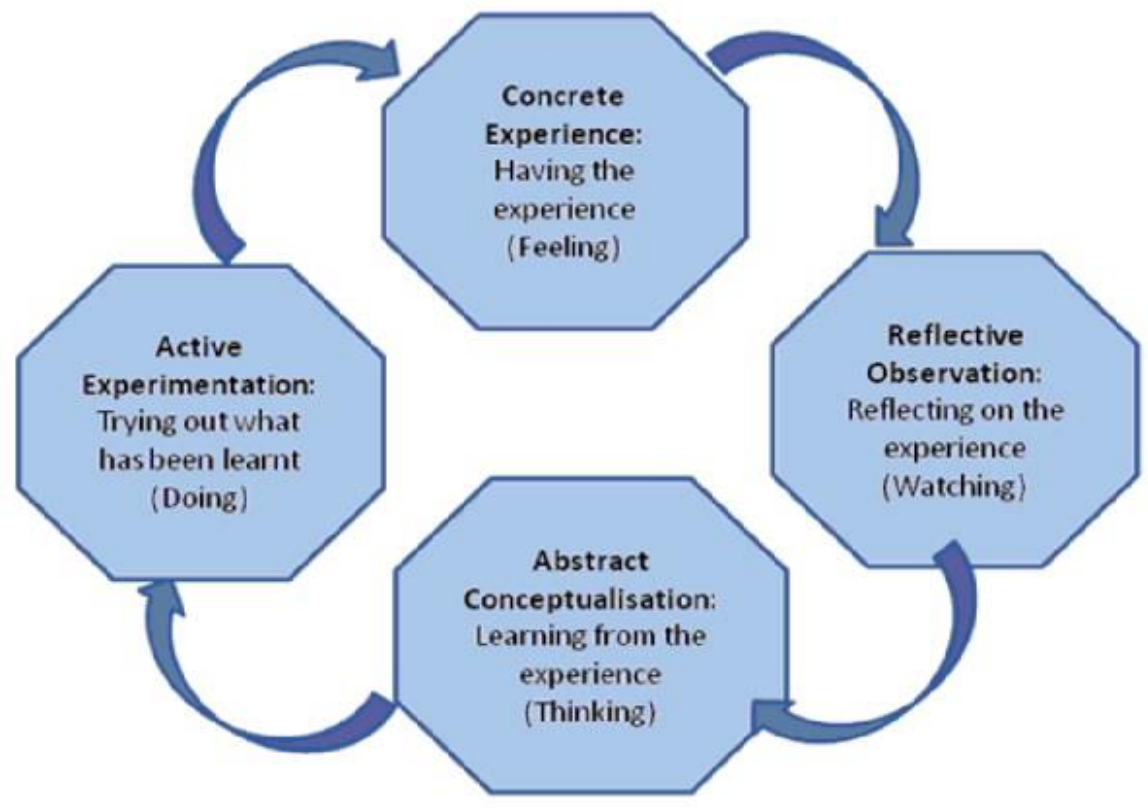

Fig. 1: Kolb's Learning Styles.

\subsection{Knowles' andragogical learning theory}

Since the women who had dumped babies and / or committed infanticide were young adults and adults, the Adult Learning Theory of Knowles was used in this study as outlined by Graig (1996). The assumptions for this study were that women who had dumped babies and / or committed infanticide as adults:

- wanted to learn what would be useful to them in order to know that they did not waste their time;

- expected to direct their learning, in other words, being actively involved in their learning;

- were more receptive to learning when the aspects of learning were relevant to the activities they were involved in;

- expected to solve their own problems and take relevant decisions to solve them; and

- Wanted a clear demonstration of the benefits it would have when they participated in the activities.

\section{Conclusion}

Baby dumping is considered as a serious criminal offence in Namibia (LAC, 2008). There are women incarcerated in Namibia for having committed either baby dumping or infanticide. Due to the nature of the crime these women committed and the thoughts of feeling rejected by their family, they fear of reintegration after being released from custody into their respective society. It is clear that these women cannot be in prison forever, therefore, there is a need to develop a means of facilitating the reintegration. It is difficult to estimate the true extent of infanticide and baby dumping in Namibia, since such cases may go unreported. However, police statistics and anecdotal information suggest that the problem is significant (LAC, 2008). Newspapers report that in most cases babies are abandoned, flushed down toilets, or dumped in pit latrines. Many are discovered on rubbish dumps, sewage works, and sewage outlets at isolated places. There are a few other indicators of the extent of the problem. For example, in April 2008 staff at Gammams Water Care Works in Windhoek estimated that they had discovered an average of 13 bodies of new-born babies each month amongst the human waste flushed down toilets. The situation of baby dumping and infanticide is not unique to Namibia as seen in the background information of this study.

Bentu (2013) states that perpetrators of baby dumping and /or infanticide are likely to have reported physical, sexual, and emotional abuse in their families of origin (especially in blended families), and subsequently in their later intimate relationships. He further points to the evidence which suggests that often the father would have denied the pregnancy and the parent(s) would have reacted with extreme anger, driving the young woman into isolation during pregnancy. Women who dump babies and / or commit infanticide could experience a similar situation. However, no study has been done to look at the experiences of these women All these aspects can give rise to negative psychological and emotion- 
al issues to these women, especially the fear they are experiencing about being released from custody.

Therefore, the researcher was inspired to explore and describe the experiences of imprisoned women who had been involved in baby dumping and / or infanticide in Namibia. The following question arises: What needs to be done to prepare and support women who have dumped babies and / or committed infanticide for being reunited or reintegrated with family and in the community? Before any assistance could be intended, it was indispensable to undertake a research study to explore their experiences. The researcher formulated the following research questions in order to direct the effort of the study in a more distinct way. What are the experiences of incarcerated women who had dumped babies and / or committed infanticide? What should be done to enable the incarcerated women who had dumped babies and / or committed infanticide to be successfully reintegrated with their family and communities? Based on the findings of the main themes of the study, four central concepts emerged from those themes; namely psychological factors, socioeconomic factors, the reintegration process, as well as a legal and ethical framework. Through consultation and member checking, it was concluded that an educational programme was suitable to prepare and support the women who had dumped babies and / or committed infanticide. The educational programme entailed the management and understanding of the psychosocial aspects, socioeconomic aspects, reintegration process, as well as the legal and ethical aspects of the women. These women are members of the society irrespective of the magnitude of the crime they had committed. They could not remain in custody forever for they were protected by the Namibian constitution that guaranteed a fair trial and sentence for every Namibian. Therefore, they needed to be prepared to return to the society. This was the reason why the researcher concluded that this study would include "a psychosocial educational programme to facilitate the reintegration of incarcerated women who had dumped babies and / or committed infanticide."

\section{References}

[1] Bentu, N. (2013). Why baby dumping? Retrieved December 12 , 2011, from http://www.dailynews.gov.bw/new-details.pnp?=3392.

[2] Botes, A. (1995). The operationalization of a research model in qualitative methodology.Curationis 1 (1) 4-9.

[3] Botes, A. (1995). The operationalization of a research model in qualitative methodology.Curationis 1 (1) 4-9.

[4] Burns, N., \& Grove, S. K. (2009). The Practice of Nursing Research: Appraisals, synthesis and generation of evidence (6th edition). St Louis, Missouri: Saunders.

[5] Burns, N., \& Grove, S. K. (2009). The practice of nursing research: Conduct critique and utilization. Philadelphia, PA: WB Saunders.

[6] Coady, N. \& Lehman, P. (2008). Theoretical perspectives for direct social work practice: Ageneralistic-eclectic approach (2nd ed.). New York: Springer.

[7] Community Agency for Social Enquiry (CASE) (2007). The situation of youth in theSouthern African development community, an overview of SADC countries. Retrieved on July 17, 2011, from http://www.ydn.org.za/publications/yes/finalexecreport.htm\#_Toc5 3811296.

[8] Creswell, J. W. (2009). Research design: Qualitative \& quantitative and mixed methods approaches, 3rd edition. Thousand Oaks, CA: Sage.

[9] Creswell, J. W. (2013). Qualitative Inquiry and Research Design Choosing Among Five Approaches (3rd ed., p. 472). Los Angeles, CA: SAGE Publications.

[10] Daily Maverick (2012).They opened their home and hearts to South Africa's abandoned babies. Retrieved on June 25, 2013, from http://www.dailymaverick.co.za/.../2012-05 17-they-opened-theirhome-and-hearts-to-south-africas-abandoned-babies.

[11] Dickoff, J., James, P. and Wiedenbach, E. (1968). Theory in practice discipline Part 1: Practice Oriented Theory. American Journal of Nursing Company. 7(5):415-451. http://dx.doi.org/10.1097/00006199-196809000-00006.

[12] Dzimiri, N. (2013). Concern over increase in baby dumping and infanticide. Retrieved June 06, 2014 from http://www. dailynews.gov.bw/new-details/.
[13] Edmonds, W. A. \& Kennedy T. D. (2013). An Applied Reference Guide to Research Designs: Quantitative, Qualitative and Mixed Methods. Sage Publications Inc.

[14] Greiner, M.E. (2001-2008). Baby Dump News. A Weekly EChronicle of Newborn Abandonment, infanticide, Safe Haven and related Issues. World Press. maddogmarley@ worldnet.att.net.

[15] Guba, E. G \& Lincoln, Y. S. (2005). Naturalistic Inquiry. London Sage. Kangandjela, L. N. \& Maupare, C. (2009). Work in progress: The Child Care and Protection Act in Namibia. University of Namibia.

[16] Kimberly, A. G. (2009). Qualitative, Quantitative and Mixed Methods Approaches to Research and Inquiry.

[17] Kopelman, L. \& Van Niekerk, A. (2005). Moral and social complexities of AIDS in Africa. In Kopelman, L \& A. Van Niekerk (Eds.), Ethics and AIDS in Africa (pp. 71-83). Claremont: David Philip Publishers.

[18] Legal Assistance Center. (2008). Gender Research and Advocacy Program. Windhoek, Namibia.

[19] Legal Assistance Center. (2010). Foster Grants. Windhoek, Namibia.

[20] Legal Assistance Center. (2013). Improvement of the implementation of the Maintenance Act. Windhoek, Namibia.

[21] Legal Assistance Centre. (1990). Know Your Constitution. Windhoek: Namib Graphics, Namibia.

[22] Mazbah, T., Abdullah, N., Jaafar, N. I. M., Tagaranao, M. S. \& Safian, Y. H. M. (2014). International Journal of Technical Research and Applications. A comparative study on punishment and preventative methods of baby dumping Malaysia Perspective. E ISSN : 2320-8163, www.ijtra.com Volume-2, Special Issue 4 (July-Aug 2014), PP. 24-28.

[23] Modie-Moroka, T. (2011). Infanticide, baby-dumping and abandonment in Botswana: Implications for research, policy and practice. In T. Maundeni \& M. Nnyepi (Eds.), Reflections on children in Botswana. The United Nations Children Fund (UNICEF), Botswana Country Office.

[24] Moseley, H. (1986). The History of Infanticide in Western Society Issues in law and medicine 346-357.

[25] Mouton, J. (2004). How to succeed in your masters and doctoral studies: A South African guide and resource book. Pretoria: Van Schaik.

[26] Polit, D. F. \& Beck, C. T. (2008). Nursing Research: Generating and Assessing Evidence for Nursing Practice, 9th Edition Philadelphia: Lippincott Williams \& Wilkins.

[27] Polit, D. F. \& Beck, C. T. (2009) the nursing Research generating and Assessing Evidence for nursing practice. Lippincott Williams \& Wilkins Philadelphia.

[28] Polit, D. F. \& Beck, C. T. (2012). Nursing Research: Generating and Assessing Evidence for Nursing Practice, 9th Edition Philadelphia: Lippincott Williams \& Wilkins

[29] Polit, D. F., \& Hungler, B. P. (2006). Nursing research principles and methods. Philadelphia, PA: Lippincott.

[30] Ramklaas, N. (2010). Baby dumping on the rise in Western Cape. Independent News. Cape Town, South Africa. Retrieved on, September 03, 2014, from http://www.news24.com/.

[31] Repko, A. F. (2012). Interdisciplinary Research Process and Theory. Sage Publications Inc. London.

[32] Sasman, D. (2010). Baby Dumping and Infanticide - Time to take stock. Retrieved June 27, 2011, from http://www.allafrica.com/stories/201008170718.html.

[33] Schwarz, B. (2003). Young Namibians and HIV/AIDS: A baseline study for UNICEF Namibia's adolescent HIV prevention programme. Windhoek: UNICEF Namibia. The Child Care and Protection Bill Namibia Revised. (2010). Retrieved June 30, 2015, from Unicef http://www.unicef.org/.../CCPA_FINAL_DRAFT_COMPLETE_cl ean_copy_09jun_2010_sent_9_July.pdf.

[34] Timms, P. (2005). Mental Health Information. Factsheet on Mental Illness after Birth. Royal College of Psychiatrists' Public Education Editorial Board. Belgrave Square. London. 